\title{
Business School International Alumni: A Story of Grit
}

\author{
Maureen Snow Andrade ${ }^{1} \&$ Shaylana Davis ${ }^{1}$ \\ ${ }^{1}$ Utah Valley University, Orem, Utah, USA \\ Correspondence: Maureen Snow Andrade, Department of Organizational Leadership, Utah Valley University, USA.
}

Received: August 19, 2020 Accepted: September 3, 2020 Online Published: September 9, 2020

doi:10.11114/ijecs.v4i1.4975 URL: https://doi.org/10.11114/ijecs.v4i1.4975

\begin{abstract}
Business is a top choice of study for international students in countries such as the U.S., UK, Australia, and Canada; however, knowledge about the post-graduation experiences of international business school graduates varies across hosting countries and is somewhat limited. Few business schools in the U.S. survey alumni to determine how their learning experiences have impacted their professional success. Fewer still have explored the role of English language proficiency for these graduates. This study collected data from online surveys to examine the on-campus and post-graduation experiences of international alumni to determine factors that impacted their academic and professional success, with an emphasis on English language development. Findings identified five themes - achievement-oriented, long-term commitment, involvement, sense of belonging, and experiential learning. Although participant success was largely due to their own grit, schools of business and their professors could do more to contribute to this success, particularly in the areas of curriculum and pedagogy.
\end{abstract}

Keywords: international students, English language learning, English language proficiency, schools of business, post-graduation, alumni

\section{Introduction}

Business schools in English-dominant countries host a large share of international students. In the U.S., $20 \%$ of all international students major in a business field (Institute of International Education [IIE], 2019); in Canada, 18\% choose business or management (Canadian Bureau of International Education [CBIE], 2018); in Australia, 43\% enroll in business (IIE, 2018), while in the UK, 26\% choose business as their field of study (IIE, 2018).

How much do business schools know about these students-both while enrolled and after graduation? Much work has been done in Australia on learning outcomes for international students, and particularly issues and approaches for English language development (Benzie, 2010; Craven, 2012; Dale-Jones, Hancock, \& Willey, 2013; Elder \& O’Loughlin, 2003; Green, 2005; Harris \& Ashton, 2011; Humphreys, Haugh, Fenton-Smith, Lobo, Michael, \& Walkinshaw, 2012; Storch \& Hill, 2008). In accounting programs, for instance, an embedded model that integrated communication skills with course content resulted in improved academic gains for international students (Hancock, Howieson, Kavanagh, Kent, Tempone, \& Segal, 2009a, 2009b; Sloan \& Porter, 2009). In the U.S., international student learning outcomes are generally assessed with those of other students with no differentiation in academic performance made between the two populations (Andrade, Evans, \& Hartshorn, 2018).

The availability of information about international students after graduation varies. Although $75 \%$ of AACSB International accredited business schools in the U.S. surveyed their alumni in 2005, this decreased to $29 \%$ by 2015 (Kelley, Tong, \& Choi; 2010; Martel \& Calderon; 2005; Pringle \& Michel, 2007; Wheeling, Miller, \& Slocombe, 2015). Interviews with deans of business schools hosting large concentrations of international students at the graduate level revealed that surveying international alumni and their employers is not a current practice in most cases although they saw value in it (Andrade, Evans, Hartshorn, \& Davis, 2019). Department heads over business programs with high international enrollments agree (Andrade et al., 2018). In Australia, where international students stay in the country and work, more information is available about employment outcomes; in many cases, these graduates do not have the English language skills needed for employment (Birrell, 2006; Benzie, 2010; Bretag, Horrocks, \& Smith, 2002; Hancock et al., 2009a, 2009b; Nyland, Forbes-Hewitt, \& Härtel, 2013).

In essence, knowledge about the learning outcomes of international business school graduates varies across hosting countries and is somewhat limited. This study explored the on-campus and post-graduation experiences of international alumni at one university to determine factors that impacted their academic and professional success, with an emphasis 
on English language development. Insights into international students' post-graduate experiences with English necessitate an understanding of their English language learning experiences while enrolled as international students. As such, the research questions are as follows:

What factors impacted English language development and goal achievement for these international alumni?

How have their English language skills and learning outcomes affected their professional success?

\section{Literature Review}

An accurate representation of the international student experience entails obtaining views from a variety of stakeholders, including international students themselves and those who host them in higher education institutions and in programs within these institutions. Students identify a range of goals for studying in the U.S. and other English-dominant countries. These include seeking a quality education, interest in a particular area of study, future career advantages, work experience in another country, an international experience, English language proficiency, immigration, and home-country financial aid (Roy, Lu, \& Loo, 2016).

According to a large-scale national survey in the U.S., students were generally satisfied with academic quality (e.g., faculty expertise, evaluation, courses), but expressed varying levels of satisfaction with other services (e.g., while academic advising received high ratings, English language courses and housing received lower ratings) (Roy et al., 2016). Additionally, challenges were predominantly associated with tuition and living costs with social connections and English proficiency being less of a concern. When students identified a mismatch in expectations and reality, they were likely to transfer to another institution. Ratings varied depending on country of origin. Nearly half of Chinese respondents, for instance, reported struggling with English compared to $24 \%$ overall, and in the case of social connections, $60 \%$ of Chinese students felt this was a problem compared to $33 \%$ for students from all countries combined. China is the top sending country to the U.S. and Australia (IIE, 2018) and the second highest to Canada, recently being surpassed by India (CBIE, 2018).

Although the preponderance of international students do not identify English language proficiency as a primary concern, professors and employers feel differently (Andrade, Evans, \& Hartshorn 2014, 2015, 2016, 2018; Andrade et al., 2019; Andrade, Evans, Hartshorn, \& Gates, 2020; Birrell, 2006; Bretag et al., 2002; Hancock et al., 2009a, 2009b; Nyland et al., 2013). The solution most commonly identified by faculty members is better admission screening, more English language or English classes, writing centers, or student self-initiated forms of help (Andrade et al., 2014, 2015, 2016, 2018; Benzie, 2010; Darlington, 2008; Ukpokodu, 2010). However, this does not address the responsibility of institutions and programs within them for helping students develop professional level English skills.

The national accrediting body in Australia recognizes this and has identified 10 good practice principles to guide institutions in their educational practices for international students (Australian Universities Quality Agency, 2009). These standards call for the integration of English language development with "curriculum design, assessment practices and course delivery" and the use of "evidence from a variety of sources to monitor and improve ... English language development activities" (p. 3). Appropriate entry pathways must be identified, and students made aware of their own responsibility for improvement in addition to that of the institution.

These principles have influenced the Australian approach for embedded rather than stand-alone English language approaches. In the U.S., the prevalent practice is the latter and occurs in the form of intensive English programs prior to admission or referral to generic academic English language courses after admission (Andrade et al., 2014, 2015, 2018; Andrade et al., 2020). The latter is often optional.

\subsection{English Language Acquisition}

Standardized English proficiency tests, commonly used as a sole measure for admission purposes, demonstrate that students have baseline academic English skills (Andrade et al., 2016). From there, they need to continue to develop what linguistics call CALP — cognitive academic language proficiency to be successful in their courses (Cummins, 1981, 2008), and progress to what might be referred to as PLEP-professional level English proficiency. CALP is characterized by abstract uses of language such as metaphors, symbols, and technical terms that involve interpretation and takes 5-7 years to develop while PLEP involves the ability to communicate effortlessly in writing and speaking in a professional context. While some errors are tolerated in the latter, in a formal, professional context, errors are largely unacceptable in written communication - a tall order for those for whom English is an additional language.

Some international students who graduate from universities in English-speaking countries have had difficulty obtaining employment. Although they are prepared with technical skills and knowledge, they lack the requisite English language proficiency (Birrell, 2006; Benzie, 2010; Nyland et al., 2013). The Business Council of Australia has observed that these students lack both English proficiency and cultural and social skills (Nyland et al., 2013). As such, they experience difficulty getting jobs in their professions compared to local graduates. 
The Common European Framework of Reference for Languages (CEFR) defines six levels of language proficiency from beginning to advanced (A1, A2, B1, B2, C1, C2) (Council of Europe, 2001). Universities generally require applicants to be in the $\mathrm{C} 1$ or advanced range for undergraduate study and at the $\mathrm{C} 2$ or mastery level for graduate studies although a B2 (upper-intermediate) may be sufficient for technical or vocational programs.

B2: Vantage - can understand the main ideas of complex text and can produce clear detailed text. Can spontaneously enter into a conversation.

C1: Effective operational proficiency - able to express oneself fluently and use the language flexibly and efficiently for social, academic and professional purposes.

C2: Mastery - can understand with ease virtually everything heard or read. Can express him/herself spontaneously, very fluently and precisely, differentiating finer shades of meaning even in the most complex situations.

Language learning is not linear; therefore, the amount of time it takes to progress at lower levels is less than at higher levels (Zanón, 2014). A larger range of knowledge and competencies are involved at the advanced level; also, learners may reach a plateau above the B1 level (Zanón, 2014). The time it takes to develop linguistic skill varies depending on "teaching methodology, learners' motivation, their reason or purpose for learning, the course book and materials used, the amount of time spent in individual study, age, background, extent of exposure to the language outside the classroom and others" (Zanón, 2014, p. 5). Variations also occur based on the home language and how different it is from the target language.

To support the nonlinearity of language acquisition argument, consider that it takes 500-600 hours to achieve B2 level proficiency, 700-800 hours for $\mathrm{C} 1$, and 1,000-1,200 hours for C2 proficiency. Contrast this with the 90-100 hours required for the A1 level (Cambridge University Press, 2013). Within each of these broadly-defined levels, a considerable range and variety of user profiles may also exist, thus making it difficult to determine advancement within a level. In other words, if students are admitted at a C1 or C2 level, they may or may not make progress within that level at least as measured by standardized proficiency tests that have been mapped to the CEFR.

Although the CEFR level descriptors are general, some providers have linked them to business communication skills as follows:

C1 - Shows employees or job applicants have the level of English required for demanding professional settings and can communicate effectively at managerial level; participate with confidence in workplace meetings; express themselves with a high level of fluency' follow an academic business course at university level; carry out challenging research.

also does not focus specifically on business-related communication (Cambridge English Language Assessment, n. d., p. 6).

In spite of this, the CEFR bands are broad and the descriptors above simply reference communicative abilities within a business context without much specificity. Also, it could be argued that the level of English required to be successful in a business course is not the same level needed to be successful in an actual position in the business world, and the fact that students are graduating from English-medium institutions without these needed skills attests to this (Birrell, 2006; Bretag et al., 2002; Nyland et al., 2013). In sum, most measures of English language proficiency are not sufficiently nuanced to determine PLEP. This needs to be defined and measured within programs and based on employer perspectives.

\subsection{English Language Development in Higher Education}

While many believe that students' proficiency will develop naturally as a result of their immersion experience, immersion does not always occur due to a lack of interaction with others both on and off campus (Andrade, 2018). Similarly, language development is not necessarily the result of coursework unless assignments are language-intensive and accompanied by targeted feedback, yet faculty members anecdotally attest to students' English improvement (Andrade et al., 2014, 2018; Andrade et al., 2020). Business faculty members are highly aware of the difficulties international students face with linguistic issues, but also have high expectations of them in terms of language usage (Andrade et al., 2019).

Students themselves indicate lacking confidence with their English abilities, having comprehension difficulties in the classroom, not feeling they have the same language competencies as domestic students, being unfamiliar with colloquial language, and experiencing challenges with writing (Robertson, Lane, Jones, \& Thomas, 2000). Teaching staff observe that international students have difficulty contributing in the classroom and that written work is a challenge to understand and evaluate (Bayley, Fearnside, Arnol, Misiano, \& Rottura, 2002; Bretag et al., 2002). Some students may 
be more accustomed to passive learning and have learned English from a grammar-focused or rote memorization approach and have difficulty transitioning to expectations for active, engaged learning and communicative use of the language (Sawir, 2005, 2011; Wong, 2004).

Also, while Australian universities may be actively striving to follow the principles of their accrediting agency, the equivalent of these principles is not present in U.S. universities, and by all accounts, departments hosting large percentages of international students typically view English language improvement as predominantly the students' responsibility followed by the university's (Andrade et al., 2015, 2016, 2018). The solution generally is to introduce more rigorous admission screening procedures that might include interviews of students whose scores are borderline or perhaps recruit students with a different mix of linguistic backgrounds (Andrade et al., 2018). In the UK, English language requirements vary for specific programs within a university whereas in the U.S., students are typically admitted into the university with one set score.

\subsection{Support v. Development}

Approaches to English language development can be conceptualized as a philosophy of support v. a philosophy of development (Arkoudis \& Starfield, 2007; Arkoudis, Baik, \& Richardson, 2012). See Figure 1. American universities typically have a support approach with stand-alone, generic English language programs and coursework (Harris \& Ashton, 2011) rather than the Australian model, which emphasizes modifying pedagogical approaches and embedding support into the curriculum (Hancock et al., 2009a, 2009b; Sloan \& Porter, 2009). Deans of graduate business programs indicate having regular visits from faculty who are concerned about students with low levels of proficiency (Andrade et al., 2019). The approach is to send these students to a writing center or an English language program and to examine admission screening mechanisms rather than equipping faculty members with alternate pedagogical strategies. Once again, the end result of international students' learning is not as visible in the U.S. as it is in Australia.

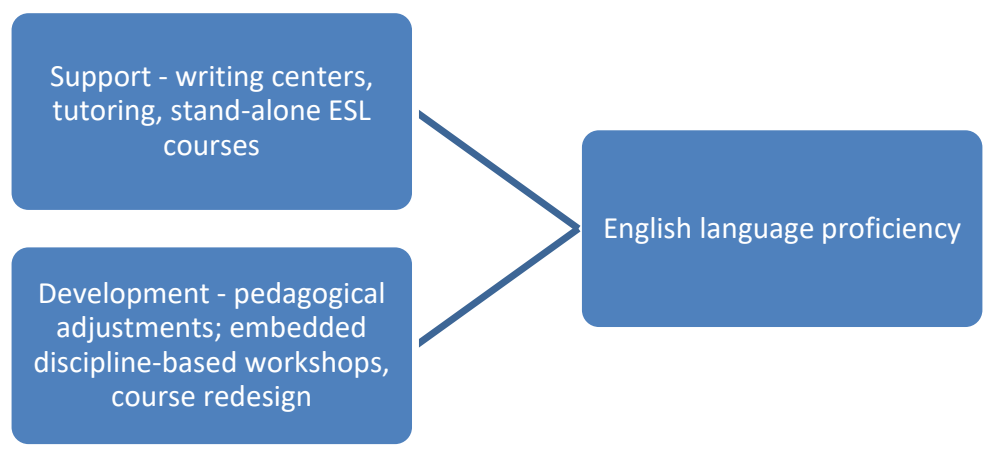

Figure 1. Support v. development

In sum, the issue of English language proficiency at the time of admission, throughout the course of study, at exit, and at post-graduation requires sophisticated teaching, learning, and evaluation approaches. In the U.S., which is the destination for the largest number of the world's globally mobile students, and in business programs within these universities, which host the majority of these students, an enormous gap exists in what is known about the English proficiency of international students, particularly at the time of exit from the university and in students' subsequent professional careers. Although recognized as something that would be of value, practices are not actively changing to address the concerns raised. The current study begins to fill this gap by obtaining the views of international alumni regarding their language development and its impact on career success.

\section{Methods}

Study participants were international students who had graduated in the past three years from a school of business in a large, regional university in the western United States. As mentioned earlier, a variety of studies representing different stakeholder perspectives are needed to fully understand the international student experience. This study fills a gap by extending previous research, with a focus on business schools, to understand the role that English proficiency has in the lives of alumni and how their academic experiences impacted that proficiency.

Data was collected by means of an online survey with open-ended questions asking alumni about the students' experiences while enrolled and after graduation, particularly related to their academic goals and professional success (see Appendix). While in-depth interviews may have generated additional understanding of the phenomena, due to the global distribution of the respondents, the survey method was adopted. Questions about the on-campus experience were designed to gain insights into how language learning experiences (e.g., support v. development) impacted post-graduation English levels and participants' professional success. The questions were also aimed at determining, 
given the experiences of the participants in their various professional contexts, what they would recommend be done differently in terms of English language development. The questions were purposively broad to allow participants to identify the most salient aspects of their experiences through the lens of a post-graduation perspective.

The majority of students (55\%) were between 25 and 34 years old; $45 \%$ were married (45\%), $45 \%$ had children, $56 \%$ were employed full-time, and $17 \%$ part-time. The total number of respondents was 31 out of the 87 who were invited for a $36 \%$ response rate. Respondents had graduated with an undergraduate degree in a business discipline within the previous three years. Three participants had also obtained an MBA from the school of business at the institution. Participants represented a variety of regions including Central/South America (Chile, Venezuela, Brazil, Guatemala), Africa (Ghana), and Asia (Japan, South Korea, China, Vietnam, Thailand, Mongolia).

Although the university does not have specific academic admission requirements (e.g., high school grades or standardized test scores), participants had met the matriculation requirements to major in business as well as institutional TOEFL requirements. Matriculation requirements consist of a set of courses that students need to complete with a certain grade in order to be accepted into a specific area of study (major) in the business school.

Business and related programs represent $19 \%$ of the institution's enrollment (approximately 6,000 students), the largest of any major. International students account for $2 \%$ of overall enrollments and $4.5 \%$ of those in the school of business. Although this percentage is not as high as it is in some institutions, there is no indication that this factor would necessarily with whom influence participants would associate-host country individuals, co-culturals, or other international students. Some research indicates that connections with host country students improves satisfaction (Hendrickson, Rosen, \& Aune, 2011) and that these connections may develop over time, particularly when students are required to work together (Rienties, Heliot, \& Jindal-Snape, 2013; Rienties, Hernandez Nanclares, Hommes, \& Veermans, 2014); however, patterns related to this vary based on culture and other factors (Montgomery \& McDowell, 2009; Rienties et al., 2014; Rienties \& Nolan-Davis, 2014).

Qualitative methodology was selected for this study to identify factors and aspects of the international student experience that may be unknown, particularly in terms of the alumni perspective. Questions were purposely broad to allow participants to identify factors most salient to their experiences. Questions included having students identify a critical incident from which, upon reflection, they gained insight into their level of success in achieving their goals for studying abroad. This technique involves collecting memorable descriptions of both positive and negative incidents related to the success of failure or a particular phenomenon (Flanagan, 1954). Student narratives collected from open-ended survey questions were coded using NVivo software to identify initial categories, meanings, and emerging themes, and test these across participants to ensure they were representative (Glaser \& Strauss, 1967; Larkin, Watts, \& Clifton, 2006). NVivo allows the researcher to assign and analyze codes in order to identify themes and examine relationships between themes. The researchers collaborated to cross-check the analysis and ensure reliability. Both kept an open mind about possible themes without any predetermination or guessing of what might emerge. The primary analysis was performed by the researcher (co-author) who had no background in English language learning and teaching.

Qualitative research is not about numbers, but about stories, or the lived experiences of participants. Its purpose is to explore rather than to test or confirm theory although qualitative studies may help establish new theories (Baker \& Edwards, 2012). The amount of data obtained should be sufficient to understand a phenomenon; this occurs when saturation is reached, or when the information becomes repetitive. Although findings cannot be generalized, conclusions are often transferable to other contexts (Trochim, 2006). In this study, data was reviewed to determine commonalities across the participants, who represented a non-homogenous sample. The recurring themes and subthemes across participants indicated that saturation had been reached. The findings provide insights for schools of business and other programs that host significant numbers of international students. They can also be examined to identify applicability to specific contexts and generate ideas for further investigation.

\section{Findings}

We next review the findings to develop a greater understanding of participants' perspectives about their learning experiences and how these experiences and related outcomes impacted their professional success. The themes indicate majority points of view. Each theme is supported with quotations from the participants to provide a direct account. Note that these accounts are verbatim from the participants without any grammatical corrections from the researchers in order to stay true to the participants' voices. Themes range from those reflecting personal attributes of the alumni to their insights into pedagogy and practice. Many of the perspectives shared were in response to the review of a critical incident, what was learned from it, and as a result, suggestions for other international students as well as schools of business. This question, in particular, elicited detailed responses. Specifics about participants' genders, ages, nationalities, cultural identities, and linguistic backgrounds is not included due to the anonymity of the survey 
responses.

\subsection{Achievement-Oriented}

Participants felt that they had been academically successful, and in particular, improved their English language skills through practice and efforts on course assignments accompanied by instructor feedback and the use of available resources. This included active participation in presentations and class discussion and language-intensive assignments such as research papers_ - "It is important to know that I took an active participation role on my learning. That made all the difference."

One participant indicated: "Every time I did the assignments and homework, I had a chance to read and understand those things that I didn't understand before and help me to improve from my mistakes in English." Another noted that specific focus on practicing writing skills and grammar and learning related strategies was valuable: "In some cases, such as with English classes, writing extensively in English helped me profusely to improve my grammar skills as well as the way I express ideas; even nowadays I use techniques I learned in English classes." Access to professors and tutors was also beneficial:

I think what has helped me the most is the availability of the professors and tutors to help me learn the material. Having small classes and access to professors, having a business and accounting lab with tutors that help has been really beneficial. I have especially enjoyed the small classes because it has allowed me to spend more time with professors and I feel this has made a large difference in my education.

Additionally, resources such as academic advisors were valuable in facilitating success: "The business school advisors were big help when I was in college. My advisor used to go through the required classes that I needed to complete and explained well in detail about the curriculum."

Another aspect of being achievement-oriented was understanding goals, monitoring performance, and learning from failure:

I think we all as international students, achieve and fail to achieve goals. For example, two main goals I got to achieve were to graduate with my bachelor's degree as well as to get an MBA. . . One of the goals I wasn't able to achieve, but that I now know I could have, was to get better grades in the first classes I took. I don't want to use it as a justification, but I feel I needed to get more serious with which classes I was taking and which classes were too advanced for me, especially with low English skills. I mean, my first academic advisors would not match the classes with my English level, they just signed me in; however, I could have been more insistent in taking classes that could have helped me improve my English, as well as teaching me about the subject and not the opposite. During my first 1 or 2 semesters, I was overwhelmed and didn't get the grades I was aiming for. Not achieving that goal was something that taught me how to be more disciplined and committed for future classes and improve my overall GPA, which I see as a positive outcome based on an adverse situation.

Another participant had a similar perspective, again demonstrating the importance of focus on goals as a means of overcoming challenges.

To achieve the main goal of graduating, I needed to surpass different adversities when building a career outside your home country: language, culture, monetary, emotional distress, legal situations that regress your professional progress. When things get tough, you need to be smart and know your limitations. You need to know when to push through, when to be patient, and always have high hopes on a desirable outcome; hope is the foundation for achieving all our goals as foreigners in an adverse environment.

This resilience in overcoming challenges and sticking to one's goals and the confidence gained from the latter, resulted not only in the rewards such as "having my diplomas hanging on the wall, seeing the face of my parents, friends and colleagues while they were cheering for me at the graduation ceremony," but knowing that "if you fully invest yourself in your goals, nothing will stop you. Because if you are successful at building a career, a family, and a life in another country, then you can do other things in other countries as well."

This theme indicates ways in which the alumni, as students, focused on goal achievement. English language development, which assisted them in achieving a degree and was valued on its own as well, occurred as the result of engagement in coursework, and as they invested themselves in improving their skills and utilizing available resources. Understanding their goals and learning from missteps was important in helping them make adjustments and in developing needed strategies, including taking greater responsibility for factors that affected their learning. The theme also demonstrates the value of specific structural factors that contributed to students' abilities to learn effectively such as availability of professors and class size. 


\subsection{Long-Term Commitment}

Not only were the alumni achievement-oriented, they also exhibited a long-term commitment, and specifically to the goal of learning English. They recognized the importance of this skill to their professional success. One participant described his English learning journey and its results:

[My English] is above adequate. I tried to put great effort into learning English the way it was spoken and written in the U.S. I isolated myself in mostly English-speaking communities, activities and social interactions. As a result, my English got better, not by going to school (which helped with mostly my grammar skills) but by living like I was an English-speaking person all the time. Nowadays, when it comes to work, I use English on a daily basis, and even though it's not as good as it was when I was living in the U.S. I consider it is still above average for someone who lived there for a few years. It helps me gain an advantage, and also puts me in situations where I know exactly how to act, and how to relate and connect with other English-speaking people.

When asked about the role of English in their current professions and their abilities in English, most alumni felt they had at least adequate skills although they still made errors: "I still have a few things here and there but I consider that my English level is appropriate for holding any type of job." Another indicated: "I still make grammar mistakes. Pronunciation and accent are not perfect. Sometimes, I have to explain things twice. But as long as you are self-confident, it doesn't really matter." One participant said the following about her achievements, indicating her continued commitment to developing her language skills:

What I have achieved is that I graduated. And I developed my English skills . . . I feel like I need to push myself harder to develop my English skills so that I can communicate with foreigners and use it in my work area. I feel like I need to push myself harder to continue studying. and do everything that I can to develop my skills.

These responses show that participants had a commitment to improving their English while in school, and in some cases, this commitment continued in the professional world. Overall, the participants recognized the advantages of English language proficiency, the importance of having confidence in their skills, and the need to compensate at times for limitations. However, the latter did not deter them from wanting to associate and form relationships with English-language speakers in professional contexts. They understood the developmental nature of English acquisition and also its advantages in their professions. They felt they had achieved professional level English language skills but recognized their weaknesses.

\subsection{Involvement}

The alumni in this study overwhelmingly indicated the importance of involvement that went beyond the classroom: "Classroom knowledge will not help you start chasing your passion. What you do outside of the classroom counts." Another aspect of involvement was as a source of emotional support: "There is no emotional support system [provided by the institution] that treats each student like a unique case, other than the friends you make in school."

One participant recommended that international students should "get involved with [the school] and the community, make other students part of [their] family, make the [community] part of [their] community . . . . [and] enjoy the experience." Another expressed a similar idea_-get "involved with locals in neighborhoods, churches, school, sports, etc." In several cases, a lack of involvement was viewed as a regret: "I regret not being active and participating in school activities to make friends with locals." Still another felt that greater involvement would have helped her overcome adversity.

I think being more involved in the extracurricular activities would have helped me feel more supported and with a greater sense of community around me in the tougher times. Since one of the things, I regularly tend to do in life is turn a regret into action, I have started to contribute more as an alumna and . . . mentor international students who ask for advice. I feel I was so focused on doing things my own way, on my own pace that I forgot that you need that sense of belonging to fully appreciate all of the aspects [the school] offers.

Another participant agreed, indicating that her "teachers and friends really wanted to help me when I had a hard time understanding in classes. They showed their love and appreciation."

One participant indicated she had not had "a local network and local friends," but associated with "mostly international students," which in retrospect, was a regret. Another explains his experience getting involved:

Connecting with other international students was natural. We had a lot in common even though most of us, were not from the same country. Living in a foreign country helps you connect with people going through the same situation; it does not matter where you are from as long as you express care, respect and responsibility.

However, forming trusting relationships with U.S. students was more of a challenge: 
Connecting and developing intercultural skills with American students was a different thing. ... When it came to U.S. students I had to size them up before trusting them . . . after that it was easier to connect and develop a friendship or a business relationship. .. . By living in a mostly American neighborhood, I had the chance to absorb and learn about American culture, the good and the bad, and that assisted me in figuring how to beneficially connect with them.

One participant explained the outcomes of involvement: "You learn SO much from other people, other cultures, and other countries that your empathy is heightened, you become more intelligent and emotionally stable, and you change from an individual with one culture to an individual with multiple cultures."

In sum, involvement was seen as the means to a fully immersive experience. This was not limited to only on-campus activities and associations but extended to the external community. Benefits of involvement included emotional support, a sense of family, enjoyment, increased ability to overcome challenges, and cultural understanding. However, a few participants regretted not being more fully involved. They saw its value, but at the time, did not fully engage due to a focus on their studies or the difficulty of getting outside the natural connections they made with other international students.

\subsection{Sense of Belonging}

Students felt largely responsible for getting involved and recognized the benefits of it; however, they also felt that others, primarily their professors, could contribute to a greater sense of belonging, and particularly in ways that would benefit their learning. A common thread throughout the responses was the need for professors to have greater understanding of international students' needs and know how to manage diversity in a more impactful way. In some cases, this implied a coordinated or integrated effort across the school of business and support units:

Learn how to single each student out in a way that makes them feel comfortable with what they are learning, with their experiences on campus, with the classes they are taking, with their level of English but most of all with the confidence to know that you as their school of business together with the international office are TRULY offering the best chance for success to this student.

Another aspect of this theme was acknowledging differences within the classroom and particularly within the international student population itself. As students, these alumni wanted to be perceived as individuals who were making contributions.

Be mindful of international students' needs. International students do not respond to situations like students from the U.S. do. We as international students, are all different. We come from different countries and that does not make us the same. What makes us similar, is that all of us make great sacrifices to come to the U.S. and improve our professional situation; however, the schools that host us and the country in general also benefits from us and our abilities.

The need for greater awareness of the diverse situations of international students was reiterated in the following statement: "The school of business needs to consider that most of the countries where students come from do not speak English and being understanding of the issues, struggles, and efforts these students make in order to succeed in the U.S." Another stated that "for the most part, professors assumed [his] English was at the level it was at, so they did little to none in order to help [him] improve it."

To address this situation, one participant recommended ways in which professors could address international students' needs and adjust their pedagogical approaches:

I believe professors should really focus on each of the international students in their class, and help them develop, not only their English skills, but also the way these students approach the class in general. Meaning, are the assignments completely understood before they are due, what are the dates and ways to take the exam. In general, I believe professors should know that each international student is different and should not be expected to speak, act or respond to certain situations like a North American student. My experience in the school of business was fine, but I was aiming for excellence and for the most part, I was left hanging.

This response provides insights into adjustments professors could make that would benefit all students.

Overall, findings related to this theme indicate that schools of business could be more strategic in creating a holistic, integrated approach to factors related to hosting diverse students, understanding their needs and the differences among them, and modifying pedagogical approaches. Generally, students did not perceive a sense of belonging from their professors in that they did not feel as though their professors really knew who they were or the struggles and issues they faced. They wanted to be understood and acknowledged to a greater degree.

\subsection{Experiential Learning}


Several of the themes demonstrate that participants gained skills valued in the workforce such as being achievement-oriented, committed, and possessing intercultural and English language skills. However, professional preparation for them was not only related to preparation in their disciplines or level of English proficiency, but to gaining practical experience through networking and actual work experience.

A recurring theme was job placement. One participant indicated: "Be prepared to provide for yourself and don't create a high expectation of staying in the U.S. with a great sponsor and job." Others felt that the school should do more to facilitate networking and job placements. One suggestion was to "try to get the bigger companies to recruit from the school. Especially the big four accounting firms." Networking events with local companies was also suggested "to build connections and improve [students'] self-confidence." This was also thought to help students develop "more perspectives, and understanding of real-life in the U.S." Another suggested that extending optional practical training beyond one year would "help [students] get awesome experience after school. They will be hired by companies faster."

Others were frustrated at the difficulty of getting a one-year practical training opportunity and also permanent employment in the U.S.

For the most part, it was all about my working permit and since I graduated, I could only work for a year at the time a lot of employers would not be comfortable hiring me only for a year. That's due to the OPT and how it is set up.

H-1B visa approval. This is very, very hard! I know it's about laws by the government but makes it hard for students to develop professionally and exercise their abilities in the workplace. We have only selected work opportunities after graduation because most employers are not willing to do a work visa.

In a very few cases, the actual degree earned was problematic and required some retooling.

My first degree was not a degree that is known in my home country. It was a challenge but the fact that I spoke English and had obtained an education in the U.S. helped me not to be unemployed. As I returned to the U.S., I knew I had to shift majors and chose a high demand field, which required a certification pursuing a career that I enjoyed more and also more job security.

In spite of these difficulties, as the previous participant stated, the degree and the related English proficiency skills opened doors: "The experience of learning new things in a different language. This always puts you at the top of the list if you return to your country."

\section{Discussion and Implications}

The findings from this study reflect the student experience in retrospect after having graduated and entered the workforce. The purpose of the study was to identify factors impacting the international student experience and how these factors affected the professional success of alumni, and particularly the role of English in this success. Minimal information has been previously gathered in this area.

Overall, responses demonstrated that these alumni felt as though their success depended primarily on themselves. They exhibited personal attributes that helped them be successful in their studies and in their careers-being goal-oriented, demonstrating long-term commitment, and seeking involvement (or wishing they had). Some of these characteristics are associated with grit, or what is defined as "perseverance and passion for long-term goals" (Duckworth, Peterson, Matthews, \& Kelly, 2007, p. 1087; Duckworth, 2016). Grit consists of courage, the ability to overcome failure, conscientiousness, a focus on achievement, confidence, and endurance (Duckworth, 2016). The alumni in this study showed evidence of grit based on the stories they told of their experiences in a U.S. school of business.

This grit, or determination in terms of goal-orientation and long-term commitment, also impacted the participants' current situations in the professional world. They reported using English on a daily basis and recognizing on-going weaknesses in their proficiency, while recognizing that they had better skills than some of those with whom they associated, and also the need for strategies to compensate when their communication was unclear. Their commitment to English language development reflected recognition of what is needed to acquire the language at a professional level rather than to achieve a short-term goal such as passing a class. In other words, they recognized the difference between a philosophy of support and development in language learning. They saw a continuing need to improve. However, participants' on-campus experiences indicated that the institution itself and its constituents did not especially reflect a philosophy of development or a commitment to helping student develop professional level English language skills.

Consequently, these alumni stories have clear implications for pedagogy and curriculum. Although the grit exhibited by the alumni positively impacted their success, the school of business and its professors could make adjustments in order to contribute more to this success. The alumni stories indicated that success was largely due to participants' grit for language acquisition rather than institutional factors. Lack of awareness regarding the backgrounds and the English 
language learning development needs reported by these alumni may be related to the relatively low percentage of international ESL speakers in the school of business $(4.5 \%)$ at the institution that hosted this study. Where populations are more concentrated, professors may be more cognizant of needs and structures may be in place to address pedagogical practices appropriate to this population. However, awareness and understanding of international students was a central concern of these alumni.

Additionally, the alumni felt that professors could adjust their teaching techniques to be more responsive to those who speak English as a second language. Guidelines for teaching English language learners in higher education are available (e.g., Higher Education Academy, 2014), and could easily be the topic of a retreat or department meeting with follow-up sessions to discuss changes made and their outcomes. Similarly, consideration of the models introduced in the literature review that entail greater integration of English skills development within the curriculum should also be considered, particularly for schools with high concentrations of international students. This includes restructuring support focusing on remediation in favor of support reflecting a developmental philosophy.

Adopting good practice principles as part of a mission statement or strategic plan would also provide greater focus on these issues. Additionally, although some evidence of high impact practices such as writing intensive assignments and constructive feedback was evident in participants' comments (e.g., see Association American Colleges \& Universities, 2011, 2015 for more information on high impact educational practices), an increase in collaborative assignments would help facilitate involvement rather than leaving this to the students to manage. Involvement also facilitates English language development. Regardless of which of these practices is adopted, measurements must be in place to determine outcomes in both English language development and other skills. It is largely unknown if graduates from schools of business in the U.S. have needed professional English language proficiency (PLEP). Thus, business schools should investigate this further by conducting needs analyses and collecting various types of data from their alumni.

Although schools of business are constrained by immigration laws in terms of offering employment opportunities, these alumni would have appreciated more opportunities for hands-on experience. This might include service learning, consulting, and internships, as well as greater facilitation of Optional Practical Training (OPT) opportunities. These opportunities not only benefit the students but are also a source of feedback to the school on curricular practices and level of preparation of graduates. They also increase involvement with the community, which participants in this study felt was vital to their overall experience.

The limitations of this study include a small sample from one institution. Also, participants were self-selected, and as such, may represent those who had either more positive or negative experiences to share than others. They were also reflecting on their experiences in retrospect, which may have altered their perspectives. Although some students may have been reluctant to respond at length to the open-ended questions due to a lack of confidence in their English writing skills or simply due to the survey method itself, these students had all successfully graduated from an English-speaking university indicating some level of proficiency in the language. Additionally, the content and length of the responses overall indicated a sincere willingness to contribute to the purpose of the study.

The limited number of participants precluded drawing conclusions about variations in the transition or post-graduation experiences of students from any one country, region, culture, or linguistic background. In spite of these limitations, the stories of these students indicate commonalities which provide insights into the goals of international students, goal achievement, the impact of their experiences post-graduation, and what institutions and schools of business can do better.

While these experiences were largely positive, much remains unknown. Future research might involve gaining insights into faculty or administrative perspectives on the issues raised by these alumni as well as conducting similar alumni studies in other contexts. Also, in spite of the contributions of this study, much remains unknown about how international graduates perform in professional business contexts. Employer perspectives are needed alongside those of alumni and professors.

\section{Conclusion}

The themes discussed in this study represent the thoughts and perspectives of former international students. Although schools of business are decreasingly obtaining the perspectives of their alumni or only collecting limited kinds of information, this study demonstrated a real need for this as well as for employer feedback. In the U.S. context (and perhaps other major English-medium study destinations with the exception of Australia), little is known about students' levels of English at the time of graduation and if they have needed professional English language skills post-graduation. In sum, while these alumni appeared fairly satisfied and also successful in their careers, their experiences demonstrated ways in which schools of business could be more responsive to the learning needs and preparation of international students. The alumni stories demonstrated a clear call for a philosophy of development aimed at English proficiency for professional success to complement students' own goal-orientation and long-term commitment; in other words, to their 
grit for language acquisition.

\section{References}

Andrade, M. S. (2018). English language development: Preparing for a business career. e-Journal of Business Education \& Scholarship of Teaching, 12(2), 118-126. Retrieved from http://www.ejbest.org/upload/e-JBEST_8_Andrade_12(2)_2018.pdf

Andrade, M. S., Evans, N. W., \& Hartshorn, J. (2015). Perceptions and realities of ESL students in higher education: An overview of institutional practices. In N. W. Evans, N. J. Anderson, \& W. G Eggington (Eds.), ESL readers and writers in higher education: Understanding challenges, providing support, pp. 18-35. New York: Routledge.

Andrade, M. S., Evans, N. W., \& Hartshorn, J. (2016). Internationalizing higher education: English language policy and practice. In B. Krishna, \& C. Foster (Eds.), pp. 188-208. Campus support services, programs, and policies for international students. Hershey, PA: IGI Global. https://doi.org/10.4018/978-1-4666-9752-2.ch010

Andrade, M. S., Evans, N. W., \& Hartshorn, K. J. (2014). Linguistic support for non-native English speakers: Higher education practices in the United States. Journal of Student Affairs Research and Practice, 51(2), 207-221. https://doi.org/10.1515/jsarp-2014-0020

Andrade, M. S., Evans, N. W., \& Hartshorn, K. J. (2018). English language development for international students: Insights from the top hosting business schools. Journal of International Business Education, 13, 79-100.

Andrade, M. S., Evans, N. W., \& Hartshorn, K. J., \& Davis, S. (2019). Good, better, best - English language development practices in graduate business programs. International Journal of Management, 17(1), 36-46. https://doi.org/10.1016/j.ijme.2018.11.006

Andrade, M. S., Evans, N. W., \& Hartshorn, K. J., \& Gates, G. (2020). Understanding diversity - Perspectives from university departments hosting global learners. Journal of Higher Education Theory \& Practice, 20(1). https://doi.org/10.33423/jhetp.v20i1.2774

Arkoudis, S., \& Starfield, S. (2007). In-course English language development and support. Canberra, Australia: Australian Education International.

Arkoudis, S., Baik, C., \& Richardson, S. (2012). English language standards in higher education: From entry to exit. Camberwell, Australia: Australian Council for Educational Research.

Association of American Colleges and Universities. (2011). The LEAP vision for learning: Outcomes, practices, impact, and employers' views. Washington, DC: Association of American Colleges and Universities. Retrieved from https://www.aacu.org/sites/default/files/files/LEAP/leap_vision_summary.pdf

Association of American Colleges and Universities. (2015). The LEAP challenge: Education for a world of unscripted problems. Washington, DC: Association of American Colleges and Universities. Retrieved from https://www.aacu.org/sites/default/files/files/LEAP/LEAPChallengeBrochure.pdf

Australian Universities Quality Agency. (2009). Good practice principles for English language proficiency for international students in Australian universities. Retrieved from http://www.aall.org.au/sites/default/files/Final_Report-Good_Practice_Principles2009.pdf

Baker, S. E., \& Edwards, R. (2012). How many qualitative interviews is enough? Southampton, UK: National Center for Research Methods.

Bayley, S., Fearnside, R., Arnol, J., Misiano, J., \& Rottura, R. (2002). International students in Victoria. People and Place, 10(2), 45-54. https://doi.org/10.1177/1035719X0200200113

Benzie, H. (2010). Graduating as a native speaker: International students and English language proficiency in higher education. Higher Education Research \& Development, 29(40), 447-459. https://doi.org/10.1080/07294361003598824

Birrell, B. (2006). Implications of low English standards among overseas students at Australian universities. People and Place, 14(4), 53-64.

Bretag, T., Horrocks, S., \& Smith, J. (2002). Developing classroom practice to support NESB students in information systems courses: Some preliminary findings. International Education Journal, 3(4), 57-69.

Bruguglio, C., \& Smith, R. (2012). Perceptions of Chinese students in an Australian university: Are we meeting their needs? Asia Pacific Journal of Education, 32(1), 17-33. https://doi.org/10.1080/02188791.2012.655237

Cambridge English Language Assessment. (n. d.). Cambridge business certificates. Guide for employers. Retrieved from http://www.cambridgeenglish.org/images/140685-bec-guide-for-employers.pdf 
Cambridge University Press. (2013). Introductory guide to the Common European Framework of Reference (CEFR) for English language teachers. Retrieved from http://www.englishprofile.org/images/pdf/GuideToCEFR.pdf

Canadian Bureau for International Education. (2018). International students in Canada. Retrieved from https://cbie.ca/infographic/

Coates, H. (2010, January). International students' engagement with effective educational practices: A cross-national comparison. AUSSE Research Briefing, 5. Retrieved from http://research.acer.edu.au/cgi/viewcontent.cgi?article=1006\&context=ausse

Council of Europe. (2001). Common European Framework of Reference for Languages. Retrieved from https://www.coe.int/en/web/common-european-framework-reference-languages/the-cefr-descriptors

Craven, E. (2012). The quest for IELTS 7.0: Investigating English language proficiency of international students in Australian universities. IELTS Research Reports. Retrieved from http://www.ielts.org/PDF/vol13_Report2.pdf

Cummins, J. (1981). Bilingualism and minority language children. Toronto: OISE Press.

Cummins, J. (2008). BICS and CALP: Empirical and theoretical status of the distinction. In B. Street \& N. H. Hornberger (Eds.), Encyclopedia of Language and Education, Volume 2: Literacy (2nd ed., pp. 71-83). New York, NY: Springer-Verlag.

Dale-Jones, G., Hancock, P., \& Keith Willey, K. (2013). Accounting students in an Australian university improve their writing: But how did it happen? Accounting Education, 22(6), 544-562. https://doi.org/10.1080/09639284.2013.847321

Darlington, M. (2008). Contrasting views: Embedding cultural diversity in the FE Art and Design curriculum. Journal of Further and Higher Education, 32(3), 263-274. https://doi.org/10.1080/03098770802220447

Duckworth, A. (2016). Grit: The power of passion and perseverance. New York: Simon \& Schuster.

Duckworth, A. L., Peterson, C., Matthews, M. D., \& Kelly, D. R. (2007). Grit: Perseverance and passion for long-term goals. Retrieved from perseverance and passion for long-term goals. Journal of Personality and Social Psychology, 92(6), 1087-1101. https://doi.org/10.1037/0022-3514.92.6.1087

Elder, C., \& O'Loughlin, K. (2003). Investigating the relationship between intensive English language instruction and band score gain on IELTS. IELTS Research Reports, 4, 207-254.

Flanagan, J. C. (1954). The critical incident technique. Psychological Bulletin, 51(4), 327-358.

Glaser, B. G., \& Strauss, A. L. (1967). The discovery of grounded theory: Strategies for qualitative research. New York: Aldine De Gruyter. https://doi.org/10.1097/00006199-196807000-00014

Green, A. (2005). EAP study recommendations and score gains on the IELTS academic writing test. Assessing Writing, 10, 44-60. https://doi.org/10.1016/j.asw.2005.02.002

Hancock, P., Howieson, B., Kavanagh, M., Kent, J., Tempone, I., \& Segal, N. (2009a). Accounting for the future: More than numbers, 1. Final report. Australian Learning and Teaching Council. New South Wales. Retrieved from citeseerx.ist.psu.edu/viewdoc/download?doi=10.1.1.169.2764\&rep=rep1\&type=pdf

Hancock, P., Howieson, B., Kavanagh, M., Kent, J., Tempone, I., \& Segal, N. (2009b). Accounting for the future: More than numbers, 2. Strategies for embedding non-technical skills into the accounting curricula. Australian Learning and Teaching Council. New South Wales. Retrieved from eprints.usq.edu.au/6333/4/Hancock_Howieson_Kavanagh_etal_v2_2009_PV.pdf

Harris, A., \& Ashton, J. (2011). Embedding and integrating language and academic skills: An innovative approach. Journal of Academic Language \& Learning, 5(2), A73-A87.

Hendrickson, B., Rosen, D., \& Aune, R. K. (2011). An analysis of friendship networks, social connectedness, homesickness, and satisfaction levels of international students. International Journal of Intercultural Relations, 35(3), 281-295. https://doi.org/10.1016/j.ijintrel.2010.08.001

Higher Education Academy. (2014). Language. https://doi.org/10.1037/h0061470

Humphreys, P., Haugh, M. B., Fenton-Smith, L. A., Michael, R., \& Walkinshaw, I. (2012). Tracking international students' English proficiency over the first semester of undergraduate study. IELTS Research Report Series, 1, 1-42. Retrieved from https://www.ielts.org/en-us/teaching-and-research/research-reports/online-series-2012-1

Institute of International Education. (2018). Project atlas. Retrieved from https://www.iie.org/Research-and-Insights/Project-Atlas/Explore-Data 
Institute of International Education. (2019). International students. Retrieved from https://www.iie.org/Research-and-Insights/Open-Doors/Data/International-Students

Kelley, C., Tong, P., \& Choi, B. J. (2010). A review of assessment of student learning programs at AACSB schools: A dean's perspective. Journal of Education for Business, 85, 299-306. https://doi.org/10.1080/08832320903449519

Larkin M., Watts, S., \& Clifton, E. (2006). Giving voice and making sense in interpretative phenomenological analysis. Qualitative Research in Psychology, 3(2), 102-120. https://doi.org/10.1191/1478088706qp062oa

Martel, K., \& Calderon, T. (2005). Assessment in business schools: What it is, where we are at, and where we need to go now. In K. Martell \& T. Calderon (Eds.), Assessment of student learning in business schools: Best practices each step of the way, 1, 1-26. Tallahassee, FL: Association for Institutional Research.

Montgomery, C., \& McDowell, L. (2009). Social networks and the international student experience. Journal of Studies in International Education, 13(4), 455-466. https://doi.org/10.1177/1028315308321994

Nyland, C., Forbes-Mewitt, H., \& Härtel, C. E. J. (2013). Governing the international student experience: Lessons from the Australian international education model. Academy of Management Learning \& Education, 12(4), 656-673. https://doi.org/10.5465/amle.2012.0088

Pringle, C., \& Michel, M. (2007). Assessment practices in AACSB-accredited business schools. Journal of Education for Business, 82(4), 202-211. https://doi.org/10.3200/JOEB.82.4.202-211

Rienties, B., \& Nolan-Davis, E. M. (2014). Understanding friendship and learning networks of international and host students using longitudinal Social Network Analysis. International Journal of Intercultural Relations, 41(July),165-180. http://dx.doi.org/doi:10.1016/j.ijintrel.2013.12.003

Rienties, B., Heliot, Y., \& Jindal-Snape, D. (2013). Understanding social learning relations of international students in a large classroom using social network analysis. Higher Education, 66(4), 489-504. https://doi.org/10.1007/s10734-013-9617-9

Rienties, B., Hernandez Nanclares, N., Hommes, J., \& Veermans, K. (2014). Understanding emerging knowledge spillovers in small-group learning settings; a networked learning perspective. In V. Hodgson, M. De Laat, D. McConnell \& T. Ryberg (Eds.), The Design, Experience and Practice of Networked Learning, 7, $127-148$. Dordrecht, Netherlands: Springer. https://doi.org/10.1007/978-3-319-01940-6_7

Robertson, M., Lane, M., Jones, S., \& Thomas, S. (2000). International students, learning environments and perceptions: A case study using the Delphi technique. Higher Education Research \& Development, 19(1), 90-102. https://doi.org/10.1080/07294360050020499

Roy, M., Lu, Z., \& Loo, B. (2016, October). Improving the international student experience: Implications for recruitment and support. New York: World Education Services. Retrieved from http://knowledge.wes.org/WES-Research-Report-Improving-Intl-Student-Experience.html

Sawir, E. (2005). Language difficulties of international students in Australia: The effects of prior learning experience. International Education Journal, 6(5), 567-580.

Sawir, E. (2011). Dealing with diversity in internationalized higher education institutions. Intercultural Education, 22(5), 381-394. https://doi.org/10.1080/14675986.2011.643136

Sloan, D., \& Porter, E. (2009). The management of English language support in postgraduate business education: the CEM model (contextualisation, embedding and mapping). International Journal of Management Education, 7(2), 51-58. Retrieved from http://nrl.northumbria.ac.uk/2375/1/IJMEFinalVersionMay2008.pdf

Storch, N., \& Hill, K. (2008). What happens to international students' English after one semester at university? Australian Review of Applied Linguistics, 31(1), 4.1-4.17. https://doi.org/10.1075/aral.31.1.02sto

Trochim, W. M. (2006). Qualitative validity. Retrieved from http://www.socialresearchmethods.net/kb/qualval.php

Ukpokodu, O. N. (2010). How a sustainable campus-wide diversity curriculum fosters academic success. Multicultural Education, 17(2), 27-36.

Wheeling, B. M., Miller, D. S., \& Slocombe, T. E. (2015). Assessment at AACSB schools: A survey of deans. Journal of Education for Business, 90, 44-49. https://doi.org/10.1080/08832323.2014.973824

Wong, J. K. (2004). Are the learning styles of Asian internationals culturally or contextually based? International Education Journal, 4(4), 154-166.

Zanón, J. (2014, January). Discussion paper for the HR Network Working Group on the UN Language Proficiency Examination. Retrieved from mituns.weebly.com/uploads/1/9/8/6/19865389/hrnetwork_cefr_report_2014.docx 


\section{Appendix}

\section{Survey Questions}

1. What helped the most in developing your English skills? How did your professors (teaching approaches, assignments, feedback, etc.) help you develop your English skills?

2. How did you develop cross-cultural skills or intercultural understanding during your studies? With whom did you mostly associate?

3. Describe a critical incident in which you felt like you had achieved your goals for coming to the U.S. to study or realized that you perhaps had not fully achieved your goals. Include as much detail as you can. Consider that you might not have recognized achievement or lack of achievement until you returned to your own country or were employed. What factors impacted your ability to achieve your goal or not achieve it?

4. Describe the most positive aspect of your experience.

5. What do you regret most about your experience?

6. What barriers, if any, did you face in finding employment?

7. Is your English adequate for what you need to do in your workplace? Please explain.

8. What recommendations would you give to others going to the U.S. to study business?

9. What recommendations would you give to schools of business that host international students?

10. Please comment on any aspect of your experience not covered in this survey that you would like to share.

\section{Copyrights}

Copyright for this article is retained by the author(s), with first publication rights granted to the journal.

This is an open-access article distributed under the terms and conditions of the Creative Commons Attribution license (http://creativecommons.org/licenses/by/4.0/). 